\title{
Suppression of Hydrogen Evolution in Acidic Electrolytes by Electrochemical $\mathrm{CO}_{2}$ Reduction
}

\author{
Christoph J. Bondue, Matthias Graf, Akansha Goyal, and Marc T. M. Koper* \\ Cite This: J. Am. Chem. Soc. 2021, 143, 279-285 \\ Read Online
}

ABSTRACT: In this article we investigate the electrochemical reduction of $\mathrm{CO}_{2}$ at gold electrodes under mildly acidic conditions. Differential electrochemical mass spectroscopy (DEMS) is used to quantify the amounts of formed hydrogen and carbon monoxide as well as the consumed amount of $\mathrm{CO}_{2}$. We investigate how the Faradaic efficiency of $\mathrm{CO}$ formation is affected by the $\mathrm{CO}_{2}$ partial pressure $(0.1-0.5 \mathrm{bar})$ and the proton concentration $(1-0.25 \mathrm{mM})$. Increasing the former enhances the rate of $\mathrm{CO}_{2}$ reduction and suppresses hydrogen evolution from proton reduction, leading to Faradaic efficiencies close to $100 \%$. Hydrogen evolution is suppressed by $\mathrm{CO}_{2}$ reduction as all protons at the electrode surfaces are used to support the formation of water $\left(\mathrm{CO}_{2}+2 \mathrm{H}^{+}+2 \mathrm{e}^{-} \rightarrow \mathrm{CO}+\mathrm{H}_{2} \mathrm{O}\right)$.

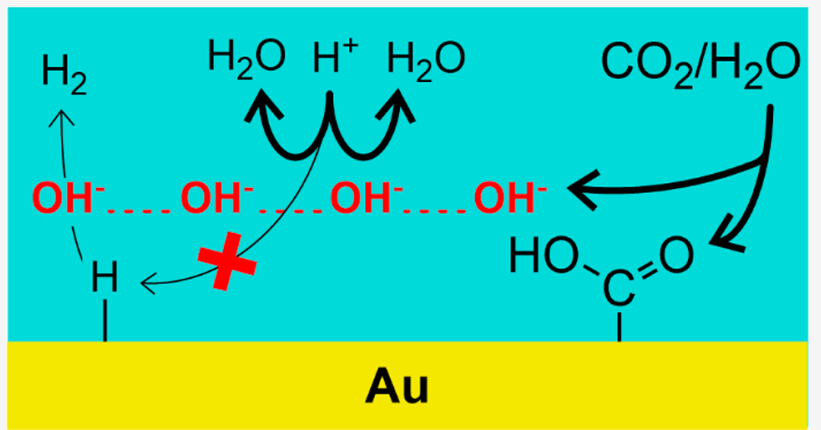
Under conditions of slow mass transport, this leaves no protons to support hydrogen evolution. On the basis of our results, we derive a general design principle for acid $\mathrm{CO}_{2}$ electrolyzers to suppress hydrogen evolution from proton reduction: the rate of $\mathrm{CO}^{-} \mathrm{OH}^{-}$ formation must be high enough to match/compensate the mass transfer of protons to the electrode surface.

\section{INTRODUCTION}

Carbon monoxide (CO), as a component in syngas, constitutes a $\mathrm{C} 1$ building block of high economic importance as it forms the basis for the synthesis of a range of chemicals. ${ }^{1}$ However, its production from fossil resources is accompanied by the emission of $\mathrm{CO}_{2}$. Electrochemical $\mathrm{CO}_{2}$ reduction to $\mathrm{CO}$ has therefore the potential to play an important role in the decarbonization of a significant portion of the chemical industry, provided the used electricity is generated by zeroemission technologies. However, to render electrochemical $\mathrm{CO}_{2}$ reduction economically beneficial, it must proceed both with high Faradaic efficiency and high energy efficiency. That is, although hydrogen is a component of syngas, it is economically more beneficial to produce $\mathrm{H}_{2}$ and $\mathrm{CO}$ in two separate processes, which are each optimized for the respective reaction.

Recently, Vennekoetter et al. investigated how both quantities are affected by the electrolyzer design. ${ }^{2}$ They found that a zero-gap arrangement in which gas diffusion electrodes (GDE) for $\mathrm{CO}_{2}$ reduction and oxygen evolution (OER), respectively, are in direct contact with a Nafion membrane achieves the highest energy efficiency among all tested designs. ${ }^{2}$ However, the Faradaic efficiency of this electrolyzer was close to zero. ${ }^{2}$ Since the current is mainly transported by protons through the Nafion membrane, the major reaction occurring at the $\mathrm{Ag}$ catalyst is the discharge of protons to hydrogen rather than the reduction of $\mathrm{CO}_{2}{ }^{2}$ Although $\mathrm{CO}_{2}$ reduction has often been reported to proceed with Faradaic efficiencies close to $100 \%,{ }^{3-5}$ these values are usually achieved at neutral $\mathrm{pH}$, where hydrogen evolution from reduction of water (not of protons) is the competing reaction. As proton reduction has an earlier onset potential than water reduction, $\mathrm{CO}_{2}$ reduction in acidic electrolytes tends to have low Faradaic efficiencies. ${ }^{6,7}$ Neutral reaction conditions and therefore higher Faradaic efficiencies for $\mathrm{CO}_{2}$ reduction can be achieved when zero-gap electrolyzers are constructed with anion-conducting membranes. ${ }^{8,9}$ However, the latter also allows the crossover of bicarbonate to the anode, thus leading to the loss of $\mathrm{CO}_{2}{ }^{2,9}$

Considering the advantages of acidic electrolytes for technical processes (higher conductivity, facile OER kinetics, ${ }^{10}$ availability of more efficient electrolyzer designs, ${ }^{2,9}$ and no crossover of $\mathrm{HCO}_{3}{ }^{-2,9}$ ), it would be interesting to achieve high Faradaic efficiencies for $\mathrm{CO}_{2}$ reduction in electrolytes of low $\mathrm{pH}$. As there are only a few examples of $\mathrm{CO}_{2}$ reduction under acidic conditions, ${ }^{6,7}$ we investigate here $\mathrm{CO}_{2}$ reduction at a gold electrode from electrolytes of mild acidity. Using the differential electrochemical mass spectrometry (DEMS) technique, ${ }^{11}$ in combination with a flow cell, ${ }^{12}$ we are able to quantify online the amounts of evolved hydrogen and $\mathrm{CO}$

Received: September 29, 2020

Published: December 24, 2020 


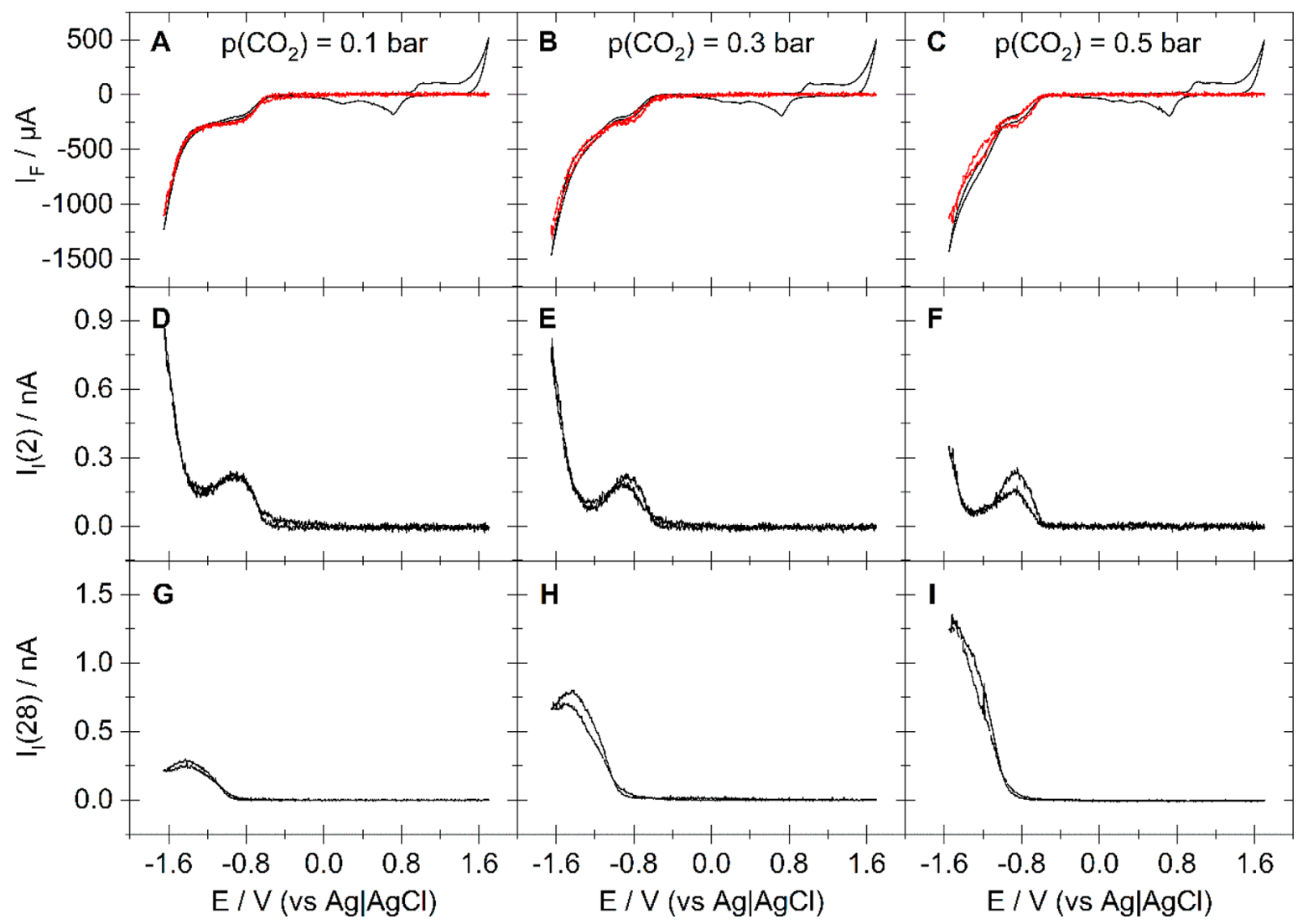

Figure 1. DEMS data for the electrochemical $\mathrm{CO}_{2}$ reduction at a polycrystalline gold electrode with a roughness factor of 20.3 (exposed geometric surface: area $\left.0.283 \mathrm{~cm}^{2}\right)$. (A-C) Measured CV (black) and CV predicted from the amounts of evolved $\mathrm{H}_{2}$ and $\mathrm{CO}$ (red); (D-F) ionic current for mass 2 corresponding to the CVs in $(A)-(C)$, respectively; (G-I) ionic current for mass 28 corresponding to the CVs in (A) $-(C)$, respectively. Electrolyte: $0.5 \mathrm{M} \mathrm{NaClO}_{4}$ containing $1 \mathrm{mM} \mathrm{HClO}$ purged with $\mathrm{Ar} / \mathrm{CO}_{2}$ mixtures featuring different $\mathrm{CO}_{2}$ partial pressures: 0.1 bar $(\mathrm{A}, \mathrm{D}$, and $\mathrm{G})$, 0.3 bar (B, E, and H), and 0.5 bar (C, F, and I). Sweep rate: $20 \mathrm{mV} / \mathrm{s}$. Flow rate: $5 \mu \mathrm{L} / \mathrm{s}$.

formed during or parallel to $\mathrm{CO}_{2}$ reduction. Furthermore, we can monitor the consumption of $\mathrm{CO}_{2}$. Our results indicate that matching the mass transport of protons to the electrode with the $\mathrm{CO}_{2}$ reduction rate can be used to suppress hydrogen evolution in a limited potential range. Our results provide another example of the importance of mass transport to suppress hydrogen evolution and to increase the Faradaic efficiency of $\mathrm{CO}_{2}$ reduction. ${ }^{13}$

\section{EXPERIMENTAL SECTION}

Chemicals and Instruments. All electrochemical measurements were conducted with an IviumStat (Ivium Technology) with a compliance voltage of $20 \mathrm{~V}$. Potentials were measured against a commercial AglAgCl reference electrode (Metrohm). $\mathrm{Ar} / \mathrm{CO}_{2}$ gas mixtures featuring a $\mathrm{CO}_{2}$ partial pressure of $0.1,0.3$, and $0.5 \mathrm{bar}$, respectively, were prepared by adjusting the flow of $\mathrm{Ar}$ and $\mathrm{CO}_{2}$ through the electrolyte via a mass flow controller. The electrolyte was prepared from $\mathrm{NaClO}_{4}$ (HPLC grade, Sigma-Aldrich) and $\mathrm{HClO}_{4}$ (suprapur, Merck Millipore).

Roughening of the Gold Electrode. The gold electrode was roughened in an electrolyte of $0.5 \mathrm{M} \mathrm{KCl}$ by exposing it to a potential program in which first a value of $-0.4 \mathrm{~V}$ vs $\mathrm{Agl} / \mathrm{AgCl}$ is held for $20 \mathrm{~s}$, from which it is then stepped for $5 \mathrm{~s}$ to $1.2 \mathrm{~V}$ vs $\mathrm{Ag} \mid \mathrm{AgCl}$. After several cycles the electrode turned black and had roughened considerably. The true surface area is determined from the charge passed during gold oxide formation in the potential region between 0.84 and $1.4 \mathrm{~V}$ vs $\mathrm{Ag} \mid \mathrm{AgCl}$, assuming a specific capacity of $420 \mu \mathrm{C} / \mathrm{cm}^{2}$.

DEMS Setup. The DEMS setup used for this study has been described earlier ${ }^{14}$ and follows the design by Wolter and Heitbaum. ${ }^{11}$ A schematic drawing of the DEMS setup can be found in a review by
Baltruschat. ${ }^{15}$ The cathode potential of the ion source of the mass spectrometer was set to $-27.5 \mathrm{~V}$ (vs ground) to avoid fragmentation of $\mathrm{CO}_{2}$ to $\mathrm{CO}^{+}$during electron impact ionization. As described earlier, this allows us to assign the evolution of a signal in the ionic current for mass 28 to the formation of $\mathrm{CO}^{14}$

The flow cell used for this study was the dual thin layer cell first introduced by Jusys et al., ${ }^{12}$ which allows defined mass transport conditions. ${ }^{12,15}$ In brief, the electrolyte purged with an $\mathrm{Ar} / \mathrm{CO}_{2}$ mixture first flows through the compartment of the working electrode. Electrochemical products formed at the working electrode are swept along with the electrolyte. In the second compartment the electrolyte flows over a porous Teflon membrane. The latter rests on a steel frit for mechanical support and is in direct contact with the vacuum of the mass spectrometer. Because of its surface tension, water cannot penetrate the pores of the Teflon membrane-however, volatile compounds in the electrolyte evaporate and are detected via mass spectroscopy. From there the electrolyte flows out of the cell and is discarded. The flow rate of the electrolyte is controlled by a syringe pump.

Calibration. Calibration of the experimental setup for hydrogen was achieved by evolving $\mathrm{H}_{2}$ from the blank electrolyte of $0.5 \mathrm{M}$ $\mathrm{NaClO}_{4}$ containing $1 \mathrm{mM} \mathrm{HClO}$ under the same experimental conditions under which the actual experiment was conducted. In the absence of $\mathrm{CO}_{2}$, hydrogen evolution at the polycrystalline gold electrode proceeds with $100 \%$ Faradaic efficiency. According to eq $1 \mathrm{a}$, the ratio of the Faradaic current due to hydrogen formation $\left(I_{\mathrm{F}}\left(\mathrm{H}_{2}\right)\right)$ divided by the number of transferred electrons $(z)$, Faraday's constant $(F)$, and the signal in the ionic current for mass $2\left(I_{\mathrm{I}}(2)\right.$, that is, the response of the mass spectrometer for mass (2) constitutes the calibration constant for hydrogen $K^{*}(2)$. 


$$
K^{*}(2)=I_{\mathrm{F}}\left(\mathrm{H}_{2}\right) / z \mathrm{FI}_{\mathrm{I}}(2)
$$

Once $K^{*}(2)$ is known, the signal in the ionic current for mass 2 measured during the $\mathrm{CO}_{2}$ reduction experiment can be converted into the partial Faradaic current for hydrogen formation.

The calibration for $\mathrm{CO}$ is achieved by the electrochemical oxidation of $\mathrm{CO}$. Because of the electrochemical consumption of $\mathrm{CO}$, the signal in the ionic current for mass 28 turns negative after baseline correction. The calibration constant for $\mathrm{CO}\left(K^{*}(28)\right)$ is obtained according to eq $1 \mathrm{~b}$ from the ratio of the Faradaic current for CO oxidation $I_{\mathrm{F}}\left(\mathrm{CO}_{\mathrm{ox}}\right)$ and the (negative) ionic current for mass 28 , $I_{\mathrm{I}}(28)$, excluding the potential region where the gold surface is oxidized. As $\mathrm{CO}$ oxidation yields $\mathrm{CO}_{2}$, we can determine the calibration constant $\mathrm{K}^{*}(44)$ for $\mathrm{CO}_{2}$ from the positive signal in the ionic current for mass $44, I_{\mathrm{I}}(44)$ and $I_{\mathrm{F}}\left(\mathrm{CO}_{\mathrm{ox}}\right)$, according to eq $1 \mathrm{c}$.

$$
\begin{aligned}
& K^{*}(28)=-\left.I_{\mathrm{F}}\left(\mathrm{CO}_{\mathrm{o} x}\right)\right|_{z \mathrm{FI}_{\mathrm{I}}(28)} \\
& K^{*}(44)=I_{\mathrm{F}}\left(\mathrm{CO}_{\mathrm{ox}}\right) / z \mathrm{FI}_{\mathrm{I}}(44)
\end{aligned}
$$

\section{RESULTS AND DISCUSSION}

Figure 1 shows DEMS experiments of $\mathrm{CO}_{2}$ reduction on a roughened polycrystalline gold electrode with a roughness factor of 20.3 in an electrolyte of $0.5 \mathrm{M} \mathrm{NaClO}_{4}+1 \mathrm{mM}$ $\mathrm{HClO}_{4}$. The top panels $(\mathrm{A}-\mathrm{C})$ show in black the measured $\mathrm{CV}$ when the electrolyte is purged with an $\mathrm{Ar} / \mathrm{CO}_{2}$ mixture featuring $\mathrm{CO}_{2}$ partial pressures of $0.1 \mathrm{bar}(\mathrm{A}), 0.3 \mathrm{bar}$ (B), and 0.5 bar (C), respectively. The middle panels below (D-F) show the ionic current for mass 2 as a function of the applied potential. The lower panels ( $\mathrm{G}-\mathrm{I}$ ) show the ionic current for mass 28 , which is proportional to the electrochemically evolved amount of CO. ${ }^{14}$ The mass spectroscopic traces were measured in parallel to the electrochemical trace.

The red curves in Figure $1 \mathrm{~A}-\mathrm{C}$ is the sum of the partial Faradaic currents of hydrogen and $\mathrm{CO}$ formation. Both quantities were determined from the ionic currents for masses 2 (shown in Figure 1D-F) and 28 (shown in Figure 1G-I) via eqs $1 \mathrm{a}$ and $1 \mathrm{~b}$, respectively. The Faradaic current expected from the sum of the partial Faradaic current of $\mathrm{H}_{2}$ and $\mathrm{CO}$ formation shows good overlap with the overall Faradaic current measured by the potentiostat below $-0.5 \mathrm{~V}$ vs $\mathrm{Agl}$ $\mathrm{AgCl}$. That is, for all $\mathrm{Ar} / \mathrm{CO}_{2}$ mixtures, the formed amounts of $\mathrm{H}_{2}$ and $\mathrm{CO}$ determined mass spectroscopically account for the charge passed in the potential region of $\mathrm{CO}_{2}$ reduction. This suggests that no other products than $\mathrm{H}_{2}$ and $\mathrm{CO}$ are formed, which is also supported by the absence of any signal in the ionic current for masses 16,27 , and 30 , indicative of methane, ethylene, and acetaldehyde, respectively. Therefore, our results obtained in mildly acidic electrolytes do not differ from $\mathrm{CO}_{2}$ reduction at gold at higher $\mathrm{pH}^{4,5}$

As the reaction is conducted under steady flow, a constant current due to mass transport limited proton reduction is expected in Figure 1. ${ }^{6,7,12,15}$ This behavior is observed both in the Faradaic current (Figure 2A) and the ionic current for mass 2 (Figure 2B) when an argon-purged electrolyte of $0.5 \mathrm{M}$ $\mathrm{NaClO}_{4}$ containing $1 \mathrm{mM} \mathrm{HClO}$ is used. The reduction process occurring when the potential is scanned below $-0.6 \mathrm{~V}$ vs $\mathrm{Ag} \mid \mathrm{AgCl}$ can be assigned exclusively to the evolution of hydrogen. This is not only indicated by the ionic current for mass 2 that mirrors the behavior of the Faradaic current but also dictated by logic as this is the only possible reduction reaction in the absence of other electroactive species in the electrolyte. Once a potential of $-0.95 \mathrm{~V}$ vs $\mathrm{Ag} \mid \mathrm{AgCl}$ is passed

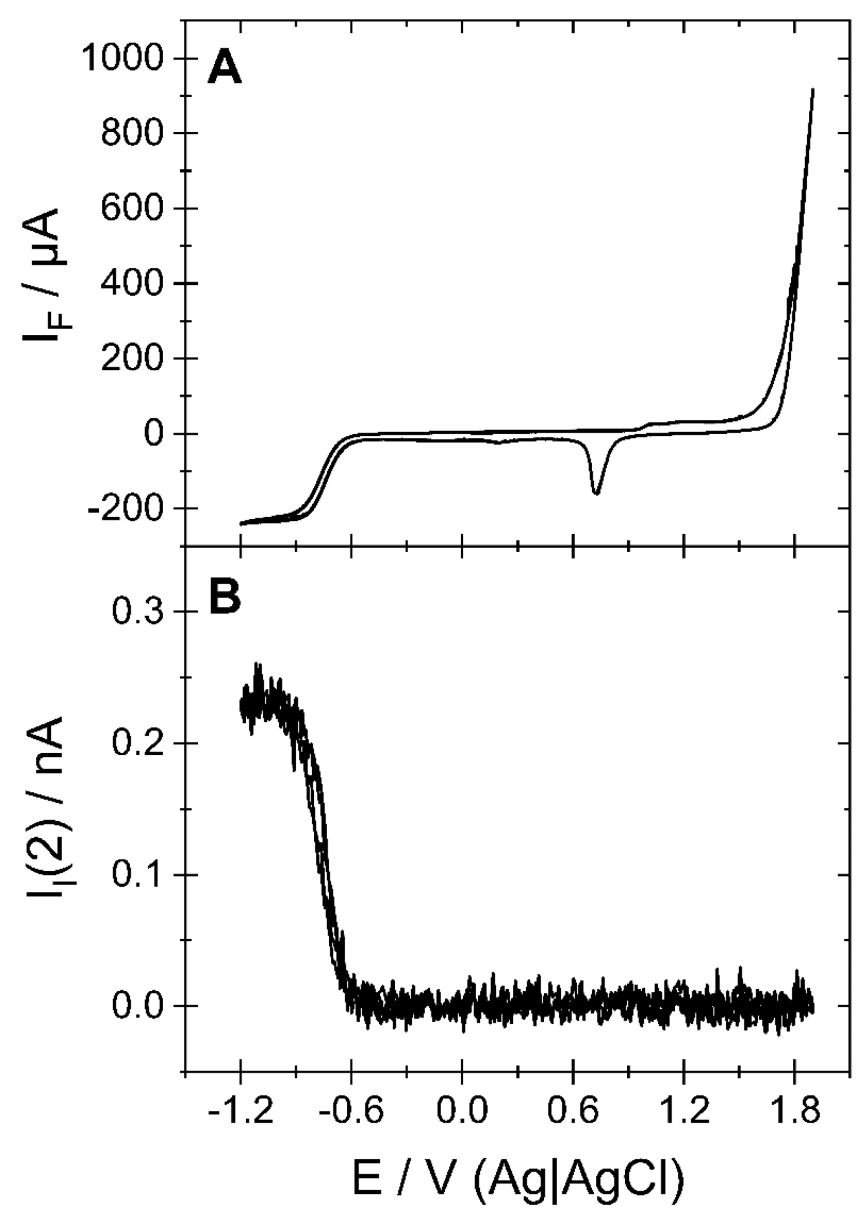

Figure 2. DEMS data of an experiment in which the electrolyte of 0.5 $\mathrm{M} \mathrm{NaClO}_{4}$ containing $1 \mathrm{mM} \mathrm{HClO}_{4}$ was purged with Ar. (A) CV; (B) ionic current for mass 2 . Sweep rate: $20 \mathrm{mV} / \mathrm{s}$. Flow rate: $5 \mu \mathrm{L} / \mathrm{s}$. Working electrode: polycrystalline gold.

in the negative-going direction, hydrogen evolution enters a steady value, indicative of a mass transport limited current.

In Figure 1, a signal evolves in the ionic current for mass 2 as a potential of $-0.6 \mathrm{~V}$ vs $\mathrm{Ag} \mid \mathrm{AgCl}$ is passed. Hence, the presence of $\mathrm{CO}_{2}$ does not affect the onset potential of proton reduction. However, diffusion limitation as in Figure 2 is not achieved. This does not become evident from the CVs shown in Figure $1 \mathrm{~A}-\mathrm{C}$, but from the ionic current for mass 2, which has a peak at $-0.9 \mathrm{~V}$ vs $\mathrm{Ag} / \mathrm{AgCl}$ and goes through a minimum at $-1.28 \mathrm{~V}$ vs $\mathrm{Ag} \mid \mathrm{AgCl}$, the current of which decreases as the $\mathrm{CO}_{2}$ partial pressure increases. In parallel, the $\mathrm{CO}$ formation rate increases (i.e., ionic current for mass 28) with increasing $\mathrm{CO}_{2}$ partial pressure. In addition, the peak in the formation rate of hydrogen at $-0.9 \mathrm{~V}$ vs $\mathrm{Ag} \mid \mathrm{AgCl}$ coincides with the onset of $\mathrm{CO}$ formation at $-0.85 \mathrm{~V}$ vs $\mathrm{Ag} \mid \mathrm{AgCl}$, suggesting that $\mathrm{CO}_{2}$ reduction suppresses hydrogen evolution. The same behavior is observed for electrolytes with lower proton concentration, as shown in Figures $\mathrm{S} 1-\mathrm{S} 3$ of the Supporting Information. Although neither $\mathrm{CO}$ nor $\mathrm{H}_{2}$ evolution enter diffusion limitation, the CVs in Figure 1 appear to feature a limiting current. This is due to the increasing partial current as a result of $\mathrm{CO}$ formation, which compensates the decrease due to decreasing $\mathrm{H}_{2}$ evolution.

As shown in reactions $2 \mathrm{a}$ and $2 \mathrm{~b}$, the reduction of $\mathrm{CO}_{2}$ to $\mathrm{CO}$ leaves an oxygen atom in oxidation state - II, which will react with protons or water to form water or two $\mathrm{OH}^{-}$ions. 


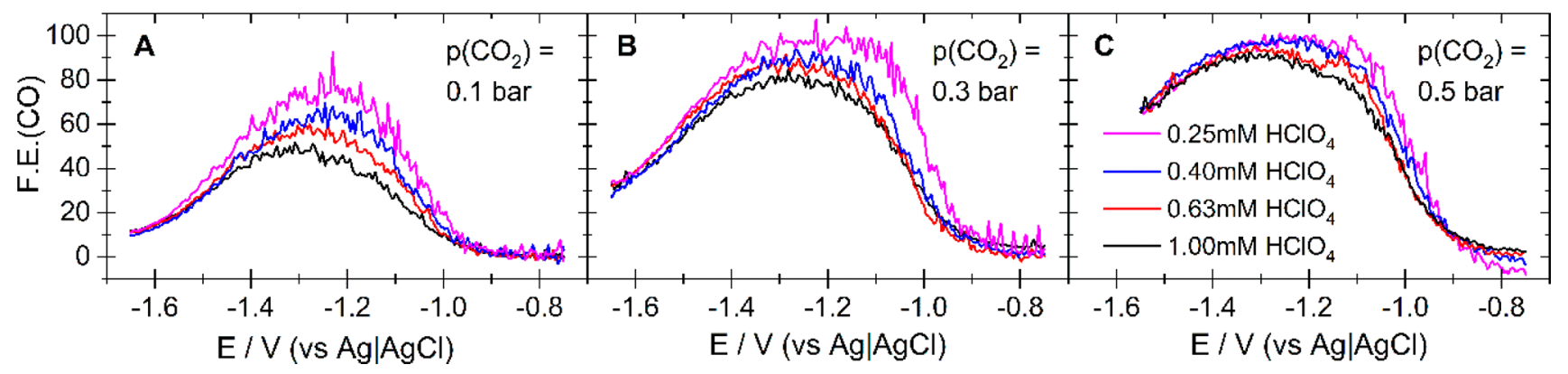

Figure 3. Faradaic efficiency of $\mathrm{CO}_{2}$ reduction at a polycrystalline gold electrode with a roughness factor of 20.3 (negative-going scan only). The electrolyte was an aqueous solution of $0.5 \mathrm{M} \mathrm{NaClO}_{4}$ containing $1 \mathrm{mM}$ (black), $0.63 \mathrm{mM}$ (red), $0.4 \mathrm{mM}$ (blue), and $0.25 \mathrm{mM}$ (magenta) of $\mathrm{HClO}_{4}$, respectively. The electrolyte was purged with $\mathrm{Ar} / \mathrm{CO}_{2}$ mixtures featuring different $\mathrm{CO}_{2}$ partial pressures: 0.1 bar (A), $0.3 \mathrm{bar}(\mathrm{B})$, and 0.5 bar (C). Sweep rate: $20 \mathrm{mV} / \mathrm{s}$. Flow rate: $5 \mu \mathrm{L} / \mathrm{s}$. The corresponding DEMS data from which the Faradaic efficiency was calculated are shown in Figure 1 and Figures S1-S3.

$$
\begin{aligned}
& \mathrm{CO}_{2}+2 \mathrm{H}_{2} \mathrm{O}+2 \mathrm{e}^{-} \rightarrow \mathrm{CO}+2 \mathrm{OH}^{-} \\
& \mathrm{CO}_{2}+2 \mathrm{H}^{+}+2 \mathrm{e}^{-} \rightarrow \mathrm{CO}+\mathrm{H}_{2} \mathrm{O}
\end{aligned}
$$

In reaction $2 \mathrm{a}_{\mathrm{CO}_{2}}$ reacts with water instead of protons because we expect a local $\mathrm{pH}$ of 7 or higher at the electrode surface. That is, at the onset of $\mathrm{CO}_{2}$ reduction, the reduction of protons has nearly reached diffusion limitation, which indicates a local $\mathrm{pH}$ of close to 7 . Because of the $\mathrm{OH}^{-}$formed in reaction $2 \mathrm{a}$ and because of water reduction, the local $\mathrm{pH}$ is bound to rise beyond 7 once the capacity of the $\mathrm{CO}_{2} / \mathrm{HCO}_{3}{ }^{-}$ buffer is exhausted. Only in the very early stages of $\mathrm{CO}_{2}$ reduction, proton discharge is not yet fully diffusion limited, which leaves some protons for reaction $2 b$ to proceed. Since $\mathrm{OH}^{-}$formed via reaction 2 a diffuses away from the electrode surfaces, it can intercept protons before they reach the electrode (reaction 3), which are then no longer available to support hydrogen evolution.

$$
\mathrm{OH}^{-}+\mathrm{H}^{+} \rightarrow \mathrm{H}_{2} \mathrm{O}
$$

A similar mechanism was previously invoked to explain lack of hydrogen evolution in mildly acidic electrolytes parallel to oxygen reduction. ${ }^{16,17}$ The combination of reactions $2 \mathrm{a}$ and 3 is equivalent to reaction $2 \mathrm{~b}$, but with the important distinction that protons do not directly react with $\mathrm{CO}_{2}$ but rather with the $\mathrm{OH}^{-}$generated. Such a mechanism is in agreement with the experimental observation that $\mathrm{CO}_{2}$ reduction is $\mathrm{pH}$-independent, ${ }^{18}$ that is, the relevant hydrogen donor for $\mathrm{CO}_{2}$ is water, not protons. ${ }^{19,20}$ The mechanistic interpretation for this observation is that $\mathrm{CO}_{2}$ is activated by electron transfer, decoupled from proton transfer, leading to a negatively charged (or polarized) $\mathrm{CO}_{2}$ intermediate, bound to the gold surface. $^{21}$

In principle, the observations made in Figure 1 could also be interpreted as the competition of reduced $\mathrm{CO}_{2}$ species ${ }^{22}$ and protons for the same adsorption sites at the gold electrode. ${ }^{23}$ Following the argumentation of Chaplin and Wragg, ${ }^{23}$ adsorption of $\mathrm{CO}_{2}$ species, which becomes increasingly favorable as overpotential or $\mathrm{CO}_{2}$ partial pressure, blocks the adsorption of protons and therefore their reduction to $\mathrm{H}_{2}$. However, if proton reduction was a surface-limited process, the rate of proton reduction should decrease with decreasing roughness of the gold electrode. The opposite is observed in Figure S4, where the experiment of Figure 1 is repeated at a smooth gold electrode. With decreasing roughness factor, proton reduction increases, thus ruling out a mechanism based on competitive adsorption. As the $\mathrm{CO}$ formation rate is limited by the reaction kinetics, it scales with the true surface area and decreases with the electrode roughness. However, the availability of protons is limited by mass transport, which scales with the geometric surface area of the electrode. Although the flux of protons remains constant, less are used during $\mathrm{CO}$ formation, which leaves more protons for hydrogen evolution.

The competition for protons has a positive effect on the Faradaic efficiency for CO formation, which can reach 100\% even in mildly acidic electrolytes. This is shown in Figure 3, which compares the Faradaic efficiency for $\mathrm{CO}$ formation as a function of potential for $\mathrm{CO}_{2}$ reduction from electrolytes with four different proton concentrations and three different $\mathrm{CO}_{2}$ partial pressures. The data from which the Faradaic efficiency in Figure 3 was calculated are shown in Figure 1 and Figures S1-S3 (Supporting Information). For any given proton concentration, the Faradaic efficiency increases with increasing $\mathrm{CO}_{2}$ partial pressure (panels $\mathrm{A}-\mathrm{C}$ ). This is due to both an increase of the $\mathrm{CO}$ formation rate and the increased suppression of hydrogen evolution. Of course, a higher proton concentration increases the rate of hydrogen evolution, and thereby lowers the Faradaic efficiency of $\mathrm{CO}$ formation. While the Faradaic efficiency of $\mathrm{CO}$ formation at the smooth electrode (c.f. Figure S5) shows the same behavior as that in Figure 3, the absolute values are consistently lower than those at the roughened gold electrode.

In Figure 3, the potential dependence of the Faradaic efficiency has a bell shape, which reaches its maximum in the potential range between -1.2 and $-1.3 \mathrm{~V}$ vs $\mathrm{Ag} \mid \mathrm{AgCl}$, from which it decreases as the potential is made more negative.

This behavior can be understood from Figure 1D-F (as well as Figures $\mathrm{S} 1-\mathrm{S} 3$ in the Supporting Information), where the amounts of evolved hydrogen start to increase again as the potential is scanned below $-1.28 \mathrm{~V}$ vs $\mathrm{Ag} / \mathrm{AgCl}$. In this potential region hydrogen evolution due to water reduction begins to take place, ${ }^{6,7}$ which is the dominant reason for the decreasing Faradaic efficiency. However, it also decreases because the $\mathrm{CO}$ formation rate either drops (Figure $1 \mathrm{G}, \mathrm{H}$ ) or its potential-dependent increase begins to flatten out (Figure 1I).

Closer inspection of Figures S1-S3 in the Supporting Information show that the formation rate of $\mathrm{CO}$, that is, the partial Faradaic current due to $\mathrm{CO}$ formation, exceeds the decrease in the rate of proton discharge. That is, fewer protons are consumed during $\mathrm{CO}_{2}$ reduction than the $\mathrm{CO}$ formation rate suggests. In the potential range prior to water reduction, 


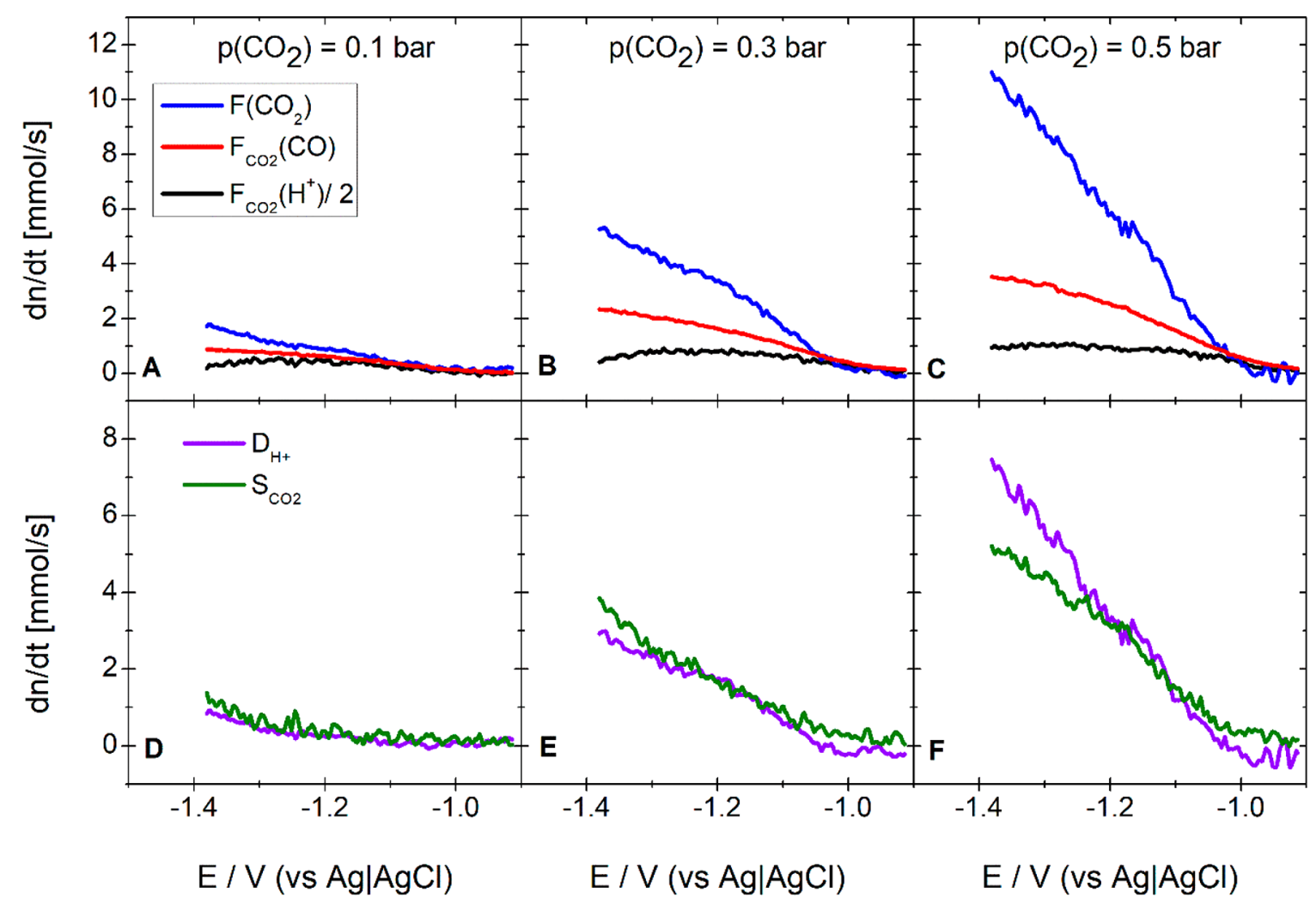

Figure 4. Top panels: Flux of protons divided by 2 (black), of $\mathrm{CO}_{2}$ (blue), and of $\mathrm{CO}$ (red) that are consumed and produced during $\mathrm{CO}_{2}$ reduction, respectively. Bottom panels: Proton deficit (violet) and $\mathrm{CO}_{2}$ surplus (olive). The electrolyte was $0.5 \mathrm{M} \mathrm{NaClO}_{4}+1 \mathrm{mM} \mathrm{HClO}$ purged with an $\mathrm{Ar} / \mathrm{CO}_{2}$ gas mixture featuring a $\mathrm{CO}_{2}$ partial pressure of 0.1 bar (A and $\left.\mathrm{D}\right), 0.3$ bar ( $\mathrm{B}$ and $\mathrm{E}$ ), and 0.5 bar $(\mathrm{C}$ and $\mathrm{F})$. Working electrode: $\mathrm{Au}(\mathrm{pc})$ (roughness factor, 20.3; exposed geometric surface, area $0.283 \mathrm{~cm}^{2}$ ). Sweep rate: $20 \mathrm{mV} / \mathrm{s}$. Flow rate: $5 \mu \mathrm{L} / \mathrm{s}$.

we can quantify the flux $\mathrm{F}_{\mathrm{CO}_{2}}\left(\mathrm{H}^{+}\right)$of protons that are consumed during $\mathrm{CO}_{2}$ reduction from eq 4

$$
F_{\mathrm{CO}_{2}}\left(\mathrm{H}^{+}\right)=-\frac{\left(I_{\mathrm{f}, \text { diff }}(2)-I_{\mathrm{f}}(2)\right)}{z F}
$$

where $I_{\mathrm{f}}(2)$ is the partial Faradaic current of hydrogen evolution determined from the ionic current for mass 2, $I_{\mathrm{f} \text {,diff }}(2)$ is the diffusion-limited current of proton reduction when no $\mathrm{CO}_{2}$ reduction takes place, $F$ is the Faraday constant, and $z$ is the number of transferred electrons. The difference $\left(I_{\mathrm{f} \text {,diff }}(2)-I_{\mathrm{f}}(2)\right)$ enters eq 4 because the current of protons diffusing to the surface (i.e., $I_{\mathrm{f} \text {,diff }}(2)$ ) minus the protons reacting to hydrogen (i.e., $I_{\mathrm{f}}(2)$ ) represent the current of protons that participate in a different reaction (i.e., $\mathrm{CO}_{2}$ reduction). In a similar way we can calculate from eq 5 the flux of $\mathrm{CO}$ formed during $\mathrm{CO}_{2}$ reduction $\left(\mathrm{F}_{\mathrm{CO}_{2}}(\mathrm{CO})\right)$

$$
F_{\mathrm{CO}_{2}}(\mathrm{CO})=\frac{I_{\mathrm{f}}(28)}{-z F}
$$

where $I_{\mathrm{f}}(28)$ represents the partial Faradaic current of $\mathrm{CO}$ formation. Furthermore, we can determine from the ionic current for mass 44 (c.f. Figure S6) the flux of $\mathrm{CO}_{2}, \mathrm{~F}\left(\mathrm{CO}_{2}\right)$, that is consumed parallel to $\mathrm{CO}$ formation. Figure 4 shows $\mathrm{F}_{\mathrm{CO}_{2}}\left(\mathrm{H}^{+}\right)$divided by $2, \mathrm{~F}_{\mathrm{CO}_{2}}(\mathrm{CO})$, and $\mathrm{F}\left(\mathrm{CO}_{2}\right)$ as a function of the applied potential.

Since the formation of 1 molecule of $\mathrm{CO}$ consumes 1 molecule of $\mathrm{CO}_{2}$ and 2 protons, the black, red, and blue curves in Figure 4 should overlap. At low overpotentials this is indeed the case in Figures $4 \mathrm{~A}-\mathrm{C}$, where because of the low reaction rate, the $\mathrm{CO}$ formation rate is low. However, at higher overpotentials in Figure 4B,C, where the formation rate of $\mathrm{CO}$ is higher because of the higher $\mathrm{CO}_{2}$ pressure, only a fraction of the consumed $\mathrm{CO}_{2}$ is actually reduced to $\mathrm{CO}$. On the other hand, the number of protons participating in the reduction of $\mathrm{CO}_{2}$ is not large enough to support the observed $\mathrm{CO}$ formation rate. We can calculate this proton deficit, $D_{\mathrm{H}^{+}}$, from eq 6:

$$
D_{\mathrm{H}^{+}}=2 F_{\mathrm{CO}_{2}}(\mathrm{CO})-F_{\mathrm{CO}_{2}}\left(\mathrm{H}^{+}\right)
$$

and the surplus of $\mathrm{CO}_{2}$ consumption $\mathrm{S}_{\mathrm{CO}_{2}}$ from eq 7 :

$$
S_{\mathrm{CO}_{2}}=F\left(\mathrm{CO}_{2}\right)-F_{\mathrm{CO}_{2}}(\mathrm{CO})
$$

With increasing $\mathrm{CO}$ formation rate, both $D_{\mathrm{H}}{ }^{+}$and $S_{\mathrm{CO}_{2}}$ (lower panels of Figure 4) increase and overlap with good agreement. The same behavior is observed in Figures S7-S9 of the Supporting Information, which present the same data as Figure 4 for electrolytes with a proton concentration of $0.63,0.4$, and $0.25 \mathrm{mM}$, respectively. The fact that $D_{\mathrm{H}^{+}}$and $S_{\mathrm{CO}_{2}}$ overlap quite well suggests that the proton deficit is compensated by $\mathrm{CO}_{2}$ forming bicarbonate near the electrode surface. That is, $\mathrm{OH}^{-}$formed during $\mathrm{CO}_{2}$ reduction via reaction $2 \mathrm{a}$ is not only neutralized by protons as in reaction 3 but also reacted with $\mathrm{CO}_{2}$ to form bicarbonate according to reaction 8 .

$$
\mathrm{OH}^{-}+\mathrm{CO}_{2} \rightarrow \mathrm{HCO}_{3}^{-}
$$

The good overlap between that $D_{\mathrm{H}^{+}}$and $S_{\mathrm{CO}_{2}}$ also means that we can completely account for the mass balance of $\mathrm{CO}_{2}$ consumption. That is, $\mathrm{CO}_{2}$ is consumed as a result of $\mathrm{CO}$ 
formation and the reaction with $\mathrm{OH}^{-}$formed during $\mathrm{CO}_{2}$ reduction as well as water reduction.

We show in the Supporting Information that $S_{\mathrm{CO}_{2}}$ equals the rate of reaction 8 (i.e., rate of bicarbonate formation), whereas the consumption of protons during $\mathrm{CO}$ formation (i.e., $\mathrm{F}_{\mathrm{CO}_{2}}\left(\mathrm{H}^{+}\right)$) equals twice the rate of $\mathrm{CO}$ formation (rate of reaction 2a) minus the rate of bicarbonate formation (rate of reaction 8). This implies that complete suppression of proton reduction requires a $\mathrm{CO}$ formation rate that is equal to or exceeds the mass transport rate of protons to the electrode surface. Only then is the formation rate of $\mathrm{OH}^{-}$, which forms according to reaction $2 \mathrm{a}$ along with $\mathrm{CO}$, sufficient to intercept all protons diffusing toward the electrode surface. We believe that this is a key guiding principle for designing an efficient electrolyzer for electrochemical $\mathrm{CO}_{2}$ reduction in acid media: it must accommodate such high $\mathrm{CO}_{2}$ reduction rates that the $\mathrm{OH}^{-}$formed as a byproduct can neutralize all protons that would otherwise participate in hydrogen evolution.

With reaction 8 we can also understand why we observe in Figure 1 that the $\mathrm{CO}$ formation rate flattens out or decreases as the potential decreases below $-1.4 \mathrm{~V}$ vs $\mathrm{Ag} \mid \mathrm{AgCl}$. At this potential water reduction leads to the additional formation of $\mathrm{OH}^{-}$, resulting in the consumption of $\mathrm{CO}_{2}$. As shown in Figures $\mathrm{S} 10-\mathrm{S} 12$, this leads even under mass transport control to a significant drop of the $\mathrm{CO}_{2}$ partial pressure at the electrode surface. The potential-dependent increase of the rate constant of $\mathrm{CO}_{2}$ reduction cannot compensate for the effect of the decreasing local $\mathrm{CO}_{2}$ concentration. As a result, the current due to $\mathrm{CO}_{2}$ reduction drops. This is not limited to the potential region of water reduction. Also, in the potential region of proton reduction the $\mathrm{CO}$ formation rate increases slightly in Figures $\mathrm{S} 1-\mathrm{S} 3$ with increasing proton concentration. This is remarkable as protons are not involved in the rate-determining step, which means that their concentration should not affect the rate of $\mathrm{CO}_{2}$ reduction. ${ }^{22,18-21}$ However, a higher proton concentration means that a larger share of $\mathrm{OH}^{-}$ formed during $\mathrm{CO}_{2}$ reduction is neutralized via reaction 3 . Therefore, a higher proton concentration maintains a higher local $\mathrm{CO}_{2}$ concentration at the electrode surface and supports indirectly a higher $\mathrm{CO}$ formation rate.

\section{CONCLUSION}

We have shown in this article that $\mathrm{CO}_{2}$ reduction suppresses hydrogen evolution from proton reduction. Despite the less negative onset potential for proton reduction compared to that for $\mathrm{CO}_{2}$ reduction, a Faradaic efficiency for $\mathrm{CO}$ formation close to $100 \%$ can be achieved in mildly acidic electrolytes. The effect of the surface roughness of the electrode shows that this phenomenon does not arise because protons and $\mathrm{CO}_{2}$ compete for the same adsorption sites. It is rather due to the consumption of protons in an acid/base reaction with $\mathrm{OH}^{-}$ formed during $\mathrm{CO}_{2}$ reduction. When all protons react off with $\mathrm{OH}^{-}$before they can reach the electrode surface, their discharge is suppressed entirely. However, $\mathrm{OH}^{-}$can also react with $\mathrm{CO}_{2}$ to bicarbonate, which manifests itself in our experiments in a higher $\mathrm{CO}_{2}$ consumption rate than expected from the rate of $\mathrm{CO}$ formation. Therefore, it is not sufficient to match the mass transport of protons with the formation rate of $\mathrm{OH}^{-}$, which equals the formation rate of $\mathrm{CO}$, to suppress hydrogen evolution entirely. Furthermore, bicarbonate formation reduces the partial pressure of $\mathrm{CO}_{2}$ at the electrode surface. This becomes particularly severe once a potential is reached at which water reduction sets in. The increased consumption of $\mathrm{CO}_{2}$ due to the formation of $\mathrm{OH}^{-}$from water reduction leads eventually to a drop in the $\mathrm{CO}$ formation rate. However, also prior to water reduction bicarbonate formation reduces the $\mathrm{CO}_{2}$ partial pressure and therefore the $\mathrm{CO}$ formation rate. In electrolytes with low proton concentration the effect is slightly larger since a larger share of $\mathrm{OH}^{-}$reacts to bicarbonate but not to water. Therefore, the proton concentration influences indirectly the rate of $\mathrm{CO}_{2}$ reduction via the local $\mathrm{CO}_{2}$ concentration, although they do not participate in the rate-determining step.

Suppressed proton reduction as described in this article is interesting as it leads to Faradaic efficiencies close to $100 \%$ for $\mathrm{CO}_{2}$ reduction in acidic electrolytes. Although this finding is limited in our work to small proton concentrations and to low partial pressures of $\mathrm{CO}_{2}$, our results suggest that proton reduction can be suppressed also in electrolytes with significantly higher proton concentrations if the $\mathrm{CO}_{2}$ reduction rate can be increased accordingly. Under industrial conditions this might be achieved by conducting $\mathrm{CO}_{2}$ reduction under high $\mathrm{CO}_{2}$ pressures and by the use of GDEs featuring high roughness factors. A high surface area (higher roughness factor), enhanced mass transport of $\mathrm{CO}_{2}$ to the electrode surface (GDE), and higher local $\mathrm{CO}_{2}$ concentrations (high $\mathrm{CO}_{2}$ pressure) increase the $\mathrm{CO}_{2}$ reduction current that can be achieved per geometric electrode area. Since the mass transport of protons scales with the geometric surface area of the electrode, the $\mathrm{OH}^{-}$formed as byproduct of $\mathrm{CO}_{2}$ reduction can neutralize all protons that arrive at the catalyst surface and that would otherwise participate in hydrogen evolution. On the other hand, a sufficiently high proton concentration is required so that the formed $\mathrm{OH}^{-}$is neutralized predominantly by protons and not by $\mathrm{CO}_{2}$. Because of higher conductivity, better OER kinetics, ${ }^{10}$ better electrolyzer design, ${ }^{2,9}$ and the absence of $\mathrm{HCO}_{3}{ }^{-}$crossover, ${ }^{2,9}$ acidic electrolytes could be beneficial for technical processes. Our experimental results are of particular relevance for $\mathrm{CO}_{2}$ reduction electrodes that follow the design principle of oxygen depolarized cathodes. ${ }^{24}$ More research is need to determine whether they are of similar consequence when the catalyst layer of a GDE is in direct contact with a solid polymer electrolyte. ${ }^{25}$

\section{ASSOCIATED CONTENT}

\section{Supporting Information}

The Supporting Information is available free of charge at https://pubs.acs.org/doi/10.1021/jacs.0c10397.

Partial Faradaic currents for $\mathrm{CO}$ and $\mathrm{H}_{2}$ formation; fluxes of $\mathrm{CO}_{2}, \mathrm{H}^{+}$, and $\mathrm{CO}$ for electrolytes with different proton concentrations; DEMS data and Faradaic efficiencies at a smooth gold electrode; local $\mathrm{CO}_{2}$ partial pressure (PDF)

\section{AUTHOR INFORMATION}

\section{Corresponding Author}

Marc T. M. Koper - Leiden Institute of Chemistry, Leiden University, 2300 RA Leiden, The Netherlands; 10 orcid.org/ 0000-0001-6777-4594; Email: m.koper@lic.leidenuniv.nl

\section{Authors}

Christoph J. Bondue - Leiden Institute of Chemistry, Leiden University, 2300 RA Leiden, The Netherlands; 10 orcid.org/ 0000-0003-3619-3230 
Matthias Graf - Leiden Institute of Chemistry, Leiden University, 2300 RA Leiden, The Netherlands; Institute for Materials Research, Helmholtz Center Geesthacht, Geesthacht 21502, Germany; O orcid.org/0000-00022065-0014

Akansha Goyal - Leiden Institute of Chemistry, Leiden University, 2300 RA Leiden, The Netherlands

Complete contact information is available at:

https://pubs.acs.org/10.1021/jacs.0c10397

\section{Author Contributions}

The manuscript was written through contributions of all authors. All authors have given approval to the final version of the manuscript.

\section{Notes}

The authors declare no competing financial interest.

\section{ACKNOWLEDGMENTS}

We gratefully acknowledge financial support from The Netherlands Organization for Scientific Research (NOW) and Shell Global Solutions in the framework of the Advanced Research Center Chemical Building Blocks Consortium (ARC$\mathrm{CBBC}$ ).

\section{REFERENCES}

(1) Rostrup-Nielsen, J. R. Syngas in perspective. Catal. Today 2002, 71 (3-4), 243-247.

(2) Vennekoetter, J.-B.; Sengpiel, R.; Wessling, M. Beyond the catalyst: How electrode and reactor design determine the product spectrum during electrochemical CO2 reduction. Chem. Eng. J. 2019, 364, 89-101.

(3) (a) Hoshi, N.; Kato, M.; Hori, Y. Electrochemical reduction of $\mathrm{CO} 2$ on single crystal electrodes of silver $\mathrm{Ag}(111), \mathrm{Ag}(100)$ and $\mathrm{Ag}(110)$. J. Electroanal. Chem. 1997, 440 (1-2), 283-286. (b) Clark, E. L.; Ringe, S.; Tang, M.; Walton, A.; Hahn, C.; Jaramillo, T. F.; Chan, K.; Bell, A. T. Influence of Atomic Surface Structure on the Activity of Ag for the Electrochemical Reduction of CO 2 to CO. ACS Catal. 2019, 9 (5), 4006-4014.

(4) Cave, E. R.; Montoya, J. H.; Kuhl, K. P.; Abram, D. N.; Hatsukade, T.; Shi, C.; Hahn, C.; Nørskov, J. K.; Jaramillo, T. F. Electrochemical $\mathrm{CO} 2$ reduction on Au surfaces: mechanistic aspects regarding the formation of major and minor products. Phys. Chem. Chem. Phys. 2017, 19 (24), 15856-15863.

(5) Mezzavilla, S.; Horch, S.; Stephens, I. E. L.; Seger, B.; Chorkendorff, I. Structure Sensitivity in the Electrocatalytic Reduction of CO 2 with Gold Catalysts. Angew. Chem. 2019, 131 (12), 3814-3818

(6) Ooka, H.; Figueiredo, M. C.; Koper, M. T. M. Competition between Hydrogen Evolution and Carbon Dioxide Reduction on Copper Electrodes in Mildly Acidic Media. Langmuir 2017, 33 (37), 9307-9313.

(7) Moreno-García, P.; Kovács, N.; Grozovski, V.; Gálvez-Vázquez, M. d. J.; Vesztergom, S.; Broekmann, P. Toward CO2 Electroreduction under Controlled Mass Flow Conditions: A Combined Inverted RDE and Gas Chromatography Approach. Anal. Chem. 2020, 92 (6), 4301-4308.

(8) (a) Aeshala, L. M.; Rahman, S. U.; Verma, A. Effect of solid polymer electrolyte on electrochemical reduction of CO2. Sep. Purif. Technol. 2012, 94, 131-137. (b) Hori, Y.; Ito, H.; Okano, K.; Nagasu, K.; Sato, S. Silver-coated ion exchange membrane electrode applied to electrochemical reduction of carbon dioxide. Electrochim. Acta 2003, 48 (18), 2651-2657.

(9) Delacourt, C.; Ridgway, P. L.; Kerr, J. B.; Newman, J. Design of an Electrochemical Cell Making Syngas $\left(\mathrm{CO}+\mathrm{H}_{2}\right)$ from $\mathrm{CO}_{2}$ and $\mathrm{H}_{2} \mathrm{O}$ Reduction at Room Temperature. J. Electrochem. Soc. 2008, 155 (1), B42.
(10) Giordano, L.; Han, B.; Risch, M.; Hong, W. T.; Rao, R. R.; Stoerzinger, K. A.; Shao-Horn, Y. pH dependence of OER activity of oxides: Current and future perspectives. Catal. Today 2016, 262, 210.

(11) Wolter, O.; Heitbaum, J. Differential Electrochemical Mass Spectroscopy (DEMS) - a New Method for the Study of Electrode Processes. Berichte der Bunsengesellschaft für physikalische Chemie 1984, 88 (1), 2-6.

(12) Jusys, Z.; Massong, H.; Baltruschat, H. A New Approach for Simultaneous DEMS and EQCM: Electro-oxidation of Adsorbed CO on Pt and Pt-Ru. J. Electrochem. Soc. 1999, 146 (3), 1093-1098.

(13) Goyal, A.; Marcandalli, G.; Mints, V. A.; Koper, M. T. M. Competition between $\mathrm{CO} 2$ Reduction and Hydrogen Evolution on a Gold Electrode under Well-Defined Mass Transport Conditions. J. Am. Chem. Soc. 2020, 142 (9), 4154-4161.

(14) Bondue, C. J.; Koper, M. T.M. A DEMS approach for the direct detection of $\mathrm{CO}$ formed during electrochemical $\mathrm{CO} 2$ reduction. $J$. Electroanal. Chem. 2020, 875, 113842.

(15) Baltruschat, H. Differential electrochemical mass spectrometry. J. Am. Soc. Mass Spectrom. 2004, 15 (12), 1693-1706.

(16) Benn, E. E.; Gaskey, B.; Erlebacher, J. D. Suppression of Hydrogen Evolution by Oxygen Reduction in Nanoporous Electrocatalysts. J. Am. Chem. Soc. 2017, 139 (10), 3663-3668.

(17) Chen, W.; Liao, L. W.; Cai, J.; Chen, Y.-X.; Stimming, U. Unraveling Complex Electrode Processes by Differential Electrochemical Mass Spectrometry and the Rotating Ring-Disk Electrode Technique. J. Phys. Chem. C 2019, 123 (49), 29630-29637.

(18) Ringe, S.; Morales-Guio, C. G.; Chen, L. D.; Fields, M.; Jaramillo, T. F.; Hahn, C.; Chan, K. Double layer charging driven carbon dioxide adsorption limits the rate of electrochemical carbon dioxide reduction on Gold. Nat. Commun. 2020, 11 (1), 33.

(19) Shen, J.; Kortlever, R.; Kas, R.; Birdja, Y. Y.; Diaz-Morales, O.; Kwon, Y.; Ledezma-Yanez, I.; Schouten, K. J. P.; Mul, G.; Koper, M. T. M. Electrocatalytic reduction of carbon dioxide to carbon monoxide and methane at an immobilized cobalt protoporphyrin. Nat. Commun. 2015, 6, 8177.

(20) Wuttig, A.; Yaguchi, M.; Motobayashi, K.; Osawa, M.; Surendranath, Y. Inhibited proton transfer enhances Au-catalyzed CO2-to-fuels selectivity. Proc. Natl. Acad. Sci. U. S. A. 2016, 113 (32), E4585-93.

(21) Birdja, Y. Y.; Pérez-Gallent, E.; Figueiredo, M. C.; Göttle, A. J.; Calle-Vallejo, F.; Koper, M. T. M. Advances and challenges in understanding the electrocatalytic conversion of carbon dioxide to fuels. Nat. Energy 2019, 4 (9), 732-745.

(22) Kortlever, R.; Shen, J.; Schouten, K. J. P.; Calle-Vallejo, F.; Koper, M. T. M. Catalysts and Reaction Pathways for the Electrochemical Reduction of Carbon Dioxide. J. Phys. Chem. Lett. 2015, 6 (20), 4073-4082.

(23) Chaplin, R. P. S.; Wragg, A. A. Effects of process conditions and electrode material on reaction pathways for carbon dioxide electroreduction with particular reference to formate formation. J. Appl. Electrochem. 2003, 33 (12), 1107-1123.

(24) Moussallem, I.; Jörissen, J.; Kunz, U.; Pinnow, S.; Turek, T. Chlor-alkali electrolysis with oxygen depolarized cathodes: history, present status and future prospects. J. Appl. Electrochem. 2008, 38 (9), $1177-1194$

(25) Higgins, D.; Hahn, C.; Xiang, C.; Jaramillo, T. F.; Weber, A. Z. Gas-Diffusion Electrode for Carbon Dioxide Reduction: A new Paradigm. ACS Energy Letters 2019, 4 (1), 317-324. 